\title{
A RESPONSABILIDADE SOCIAL NAS UNI- VERSIDADES: ENSINO, INVESTIGAÇÃO E EXTENSÃO
}

\author{
SÓNIA MELO DA SILVA \\ UNIVERSIDADE DO MINHO \\ BRAGA, PORTUGAL \\ SONIA.C.MELO.SILVA@GMAIL.COM \\ TERESA RUÃO \\ UNIVERSIDADE DO MINHO \\ BRAGA, PORTUGAL \\ TRUAO@ICS.UMINHO.PT \\ GISELA GONÇALVES \\ UNIVERSIDADE DA BEIRA INTERIOR \\ COVILHÃ, PORTUGAL \\ GISELA.UBI@GMAIL.COM
}




\section{A RESPONSABILIDADE SOCIAL NAS UNIVERSIDADES: ENSINO, IN- VESTIGAÇÃO E EXTENSÃO}

Resumo: Com este estudo pretende-se mostrar que o comportamento socialmente responsável nas universidades se materializa através das suas atividades de ensino, investigação e extensão.

A metodologia incluiu entrevistas com especialistas em responsabilidade social de universidades públicas portuguesas. Os resultados mostraram que existe uma consciência da relevância destes três pilares no compromisso social universitário.

Palavras-chave: Comunicação em Instituições de Ensino Superior, Responsabilidade Social, Missão, Ensino, Investigação, Extensão.

\section{INTRODUÇÃO}

As instituições de ensino superior representam espaços de cultura e conhecimento, dos quais se espera um impacto positivo para com o desenvolvimento cultural, económico, científico e social. E estas instituições têm tentado dar resposta às solicitações e desafios societais, que lhes são constantemente colocados, reforçando o seu compromisso para com a responsabilidade social.

Neste quadro, a posição que aqui se defende é que a responsabilidade social é um ativo cada vez mais importante nas instituições de ensino superior portuguesas, em particular nas universidades públicas, e que o seu cumprimento se faz através de esforços de ação nos três pilares da missão destas instituições: ensino, investigação e extensão. Assim, é objetivo do presente estudo compreender e discutir a relevância da responsabilidade social nas universidades públicas portuguesas, bem como debater a forma como os três pilares da sua missão se destacam e se articulam como mecanismos responsáveis pela concretização de um comportamento socialmente responsável, que, em último, deverá contribuir para o progresso da sociedade.

Para estudar este fenómeno ter-se-ão como referência as instituições de ensino superior públicas portuguesas, já que o seu estatuto público aumenta o grau de compromisso que devem ter com o desenvolvimento das sociedades. Como método de análise do fenómeno, recorreu-se à entrevista (semi-estruturada) com especialistas em responsabilidade social nas universidades portuguesas, nomeadamente, os diretores de comunicação (pois, habitualmente, o pelouro da responsabilidade social está associado aos ga- 
binetes de comunicação).

Esta investigação dividir-se-á em duas partes. Num primeiro momento realizar-se-á uma revisão da literatura que apresentará e discutirá o conceito de responsabilidade social, assim como a sua aplicação no contexto das universidades. A segunda parte, de cariz empírico, inclui a análise e discussão das entrevistas realizadas, através das quais se debaterá a relevância do conceito e das práticas de responsabilidade social nas universidades públicas portuguesas e a sua manifestação através do ensino, da investigação e da extensão.

\section{RESPONSABILIDADE SOCIAL: UMA REALIDADE PRESENTE NAS ORGANIZAÇÕES}

A problemática relativa às relações entre ética, organizações e sociedade, de que a teoria da Responsabilidade Social é herdeira, emergiu nos anos 1960 nos Estados Unidos da América (Kreitlon, 2004). Segundo Nejati, Shafaei, Salamzadeh e Mohammadreza (2011), é desde a segunda metade do século XX que a questão da responsabilidade social nas organizações vem sendo debatida. Contudo, tal como afirmam Vasilescu, Barna, Epure e Baice (2010), atualmente, esta noção, vai muito além da filantropia do passado. Na verdade, espera-se que as empresas e instituições apresentem contributos reais e efetivos para o desenvolvimento sustentável, capaz de dar respostas aos problemas e desafios da sociedade.

Assim, ainda que a discussão sobre a responsabilidade social organizacional não seja muito recente, a sua aplicação real nas empresas e instituições intensificou-se nos últimos anos. Para Pinto (2009) esta surgiu num momento de crise de confiança nas organizações. Tal visão é partilhada por Maciel, Kowalsky e Menezes (2009) que relacionam o seu aparecimento com uma maior pressão dos públicos pela transparência dos negócios. Pontes e Possamai (2001) complementam esta tese ao afirmar que os motivos económicos e competitivos, agregados à pressão para prestar atenção à melhoria das condições sociais do meio envolvente, foram os grandes impulsionadores das práticas socialmente responsáveis nas empresas e instituições.

A responsabilidade social pode, então, ser definida como o compromisso que uma organização deve ter para com a sociedade, expresso por meio de atos e atitudes que a afetem positivamente (Pinto, 2009). Ou seja, esta é representada por todo o comportamento organizacional que contribua 
para a melhoria da qualidade de vida das sociedades. Nessa linha de entendimento, Ribeiro e Magalhães (2014) vêm a responsabilidade social como um conjunto de ações e processos que têm como objetivo responder às solicitações do ambiente de maneira adequada e efetiva, do ponto de vista ético. E Vasilescu (2010) corrobora esta tese ao entender a responsabilidade social como um ativo segundo o qual as empresas e instituições integram preocupações sociais e ambientais nas suas operações comerciais e na sua interação com outras partes interessadas. Dahan e Senol (2012) complementam esta visão ao definirem, igualmente, a responsabilidade social como o ativo responsável pelo estabelecimento de metas organizacionais compatíveis com o desenvolvimento da sociedade, e como o mecanismo que facilita a relação de ética e transparência com todos os públicos envolvidos. $\mathrm{Na}$ verdade, as organizações não operam num ambiente isolado e as suas ações afetam o ambiente externo. Nesse sentido, devem ser capazes de equilibrar o seu desempenho económico com os impactos sociais que geram (Nejati et al., 2011). Sgorla (2009) reforça esta ideia, defendendo que a responsabilidade social foi pensada e desenvolvida como uma tentativa de, através de uma valorização da conduta ética, minimizar a distância entre os interesses económicos e sociais da organização.

Graças a todo este pensamento produzido ao longos dos últimos anos, a responsabilidade social já não é vista hoje como uma opção, mas como uma condição para o bom desempenho das organizações que, são observadas como agentes de desenvolvimento local (Balonas, 2014). Pontes \& Possamai (2002) argumentam que, como existe uma grande interação entre a organização e o seu meio, se esta não acompanhar as mudanças ocorridas no ambiente e se não for capaz de se adaptar, a sua sobrevivência ficará comprometida. Assim, não é de estranhar que a responsabilidade social se tenha estendido a todo o tipo de empresas e instituições. Insiste-se, cada vez mais, que estas devem promover práticas orientadas para o âmbito social, defensoras do meio ambiente e dos direitos humanos, no pressuposto de que precisam de ir além do desenvolvimento da sua tarefa básica e de que devem considerar, também, os impactos que a sua atividade tem junto dos seus públicos e do meio ambiente envolvente (Ribeiro \& Magalhães, 2014). De resto, os públicos são cada vez mais exigentes e buscam perceber as ações organizacionais de responsabilidade para com a sociedade e que estão para além do lucro (Reis \& Bandos, 2012). Para Vasilescu et al. (2010), mais do que nunca, as partes interessadas exigem que as empresas 
e instituições operem de forma responsável, de acordo com os valores de transparência e prestação de contas à comunidade em que operam. Assim, a responsabilidade social torna-se fundamental para o desenvolvimento e crescimento das organizações, visto que a sociedade lhes exige, para além do fornecimento de produtos/serviços de qualidade, uma postura ética e social irrepreensível (Reis e Bandos, 2012).

Contudo, não é só a sociedade que sai privilegiada com as ações de responsabilidade social. As próprias organizações têm ganhos com a adoção destas medidas. Sgorla (2009) adianta que, com as práticas socialmente responsáveis, as organizações conseguem, também, potenciar a sua visibilidade nos mercados e despertar nos públicos uma imagem positiva. Pontes e Possamai (2002) destacam esta abordagem, referindo que uma organização socialmente responsável ganhará competitividade através do reforço da sua imagem positiva diante da comunidade, do que resulta uma maior visibilidade, aceitação e potencial. Aliás, para Balonas (2014), a reputação é o ganho mais óbvio que as organizações terão, sendo que, num segundo nível, o ganho é emocional, pois, uma empresa ou instituição sensível aos problemas sociais ganha identificação emocional. Além disso, quando as ações de responsabilidade social são implementadas adequadamente no interior da organização, é possível alcançar uma vantagem competitiva (Dahan e Senol, 2012). A gestão socialmente responsável é aquela em que os seus valores passam a permear todas as instâncias da organização, fazendo parte da lógica que a conduz (Sgorla, 2009). Assim, esta dimensão deve estar embebida na missão, visão, valores e ser partilhada pelos públicos da organização (Balonas, 2014). Quando incorporadas na estratégia organizacional, as ações socialmente responsáveis tornam-se mais eficientes e com maior possibilidade de alcançar resultados duradouros.

Em suma, hoje a responsabilidade social já não é vista como uma opção para as organizações, mas como uma condição para o seu bom desempenho. Desta forma, não é de estranhar que, atualmente, se tenha estendido a todo o tipo de organizações onde se incluem as universidades, como relevantes espaços de progresso da sociedade.

\section{RESPONSABILIDADE SOCIAL NAS INSTITUIÇÕES DE ENSINO SUPE- RIOR}

A universidade tradicional dos séculos XIX e XX exerceu o papel privile- 
giado de difusão do conhecimento e da cultura, concentrando-se na formação de profissionais voltados para os aspetos académicos, mas com pouca interação com os problemas e necessidades da sociedade (Pompeu, 2011). Atualmente, esta é uma realidade ultrapassada, num momento em que a estas instituições se fazem maiores exigências de contribuição social (Sousa Santos, 1994). E esta discussão, sobre o seu papel sociocultural, vem ocupando lugar no espaço público e nas próprias universidades (Ribeiro, 2013). Assim, parece caber às instituições de ensino superior adaptarem-se à cobrança efetiva da sociedade, dando resposta às questões do desenvolvimento socioeconómico das nações e orientando-se para a solução de problemas reais (Pompeu, 2011).

Neste cenário de pressões externas por comportamentos socialmente responsáveis, as universidades, como instituições focadas na educação e formação de seres humanos e como difusoras de conhecimento e de cultura, assumem um papel de destaque. Estas devem posicionar-se como vanguardistas no processo de desenvolvimento económico, político e cultural, em prol de uma sociedade melhor (Ribeiro, 2013). Para Sousa Santos (2004) só estas instituições podem garantir uma resposta empenhada e criativa aos desafios da responsabilidade social. Reis e Bandos (2012) destacam o seu compromisso maior com a responsabilidade social ao lembrar que thes cabe a formação tanto profissional, como ética e moral dos estudantes que, mais tarde, serão responsáveis pelo desenvolvimento da sociedade. Esta perspetiva é partilhada por Pompeu (2011) que defende que as universidades têm a função de formar indivíduos altamente qualificados, capazes de interferir no progresso económico e social. E Maciel et al.. (2009) vão mais longe, ao pensá-las como instituições de referência na sociedade, que devem implementar um compromisso socialmente responsável numa perspetiva que as coloque como exemplo para as restantes organizações. Ou seja, dado o seu protagonismo intrínseco no progresso social, cabe-lhes uma conceção mais ampla de responsabilidade social, de participação na valorização das comunidades e de intervenção nos problemas sociais (Sousa Santos,1994).

Neste quadro, é possível afirmar que as universidades públicas se destacam no processo de desenvolvimento social. Tal como afirma Hegde (2005), devido aos seus fatores históricos e às suas fontes de financiamento, espera-se que estas instituições de ensino tenham maior propensão para protagonizar ações que desencadeiam o progresso económico e social. Estas devem representar um modelo que, apoiado pelo estado, seja capaz de evoluir 
dando reposta às necessidades da sociedade, sendo, assim, responsáveis por servir o interesse público, adaptando-se às constantes alterações das carências e desejos da sociedade (Bisset, 2014).

A responsabilidade social nas universidades diz, então, respeito à forma como estas organizações respondem às solicitações sociais através das suas ações, contribuindo para a construção de uma sociedade mais democrática, mais sustentável, culturalmente melhor preparada e economicamente mais forte (Ribeiro e Magalhães, 2014). Pelo que Nejati et al. (2011) descrevem estas instituições como os centros de criação e partilha de conhecimento, desempenhando um papel decisivo na resolução dos problemas da sociedade, garantindo um futuro sustentável. Para Pinto (2009), estas representam espaços privilegiados de produção de conhecimento e de formação de cidadãos e, nesse sentido, devem ser responsáveis por mobilizar o desenvolvimento de ações que auxiliem na busca de respostas às problemáticas que emergem na sociedade. Assim, as universidades precisam de definir, no seu planeamento institucional e pedagógico, projetos que promovam o desenvolvimento científico, cultural, tecnológico e social de acordo com as necessidades da sociedade, envolvendo-se, de uma forma responsável, com a mesma (Pompeu, 2011).

Requer-se, atualmente, destas instituições, uma educação que prepare os estudantes para o exercício da cidadania e uma investigação que esteja voltada para a resolução de problemas da comunidade, alinhando-se num modelo de desenvolvimento que privilegie, além do crescimento da economia, a promoção da qualidade de vida (Ribeiro e Magalhães, 2014). Desta forma, o seu comportamento e ações devem refletir-se positivamente na sociedade, através de atividades de ensino, investigação e extensão, que são os pilares da sua missão institucional.

\section{ENSINO, INVESTIGAÇÃO E EXTENSÃO AO SERVIÇO DA RESPONSA- BILIDADE SOCIAL}

A orientação para o progresso social está (como sempre esteve) no âmago do sistema universitário, que gera capital cultural e social através das suas ações de ensino, investigação e extensão (Ribeiro e Magalhães, 2014). Estas instituições de ensino são, pois, o lócus que articula ensino, investigação e extensão e que, desta forma, não podem deixar de contribuir para o desenvolvimento sustentável da sociedade (Pinto, 2009). Reis e Ban- 
dos (2012) corroboram esta tese ao afirmar que estas devem planear as suas atividades de ensino e investigação de acordo com as necessidades da sociedade. De facto, o ensino a investigação e a extensão constituem a tríplice função das instituições de ensino superior e também o eixo central da sua responsabilidade social, já que contribuem para o desenvolvimento científico, social, político, económico e cultural.

Parece então que, embora as universidades estejam centradas nas suas atividades de transferência de conhecimento como percursoras de ações socialmente responsáveis, também o ensino e a investigação têm um importante papel neste fenómeno. De acordo com Pinto (2009), não é apenas através da extensão que estas afirmam o seu compromisso social, pois, o ensino e a investigação também têm um papel importante no que respeita aos compromissos sociais que se esperam destas instituições, sendo responsáveis por contribuir para a produção de novos conhecimentos científicos e para o desenvolvimento de ações que vão ao encontro das necessidades sociais. Pompeu (2011) assegura, também, que as atividades de ensino e investigação resultam na criação de condições que promovem a democracia, a cidadania e a justiça social. As universidades são responsáveis pela formação de indivíduos dotados de consciência crítica sobre o mundo, capazes de trabalhar em prol de sociedades melhores e constituem, ainda, o centro da criação científica e cultural, colaborando para o crescimento e progresso da sociedade em todas as suas vertentes. Estas afirmações mostram que não só a extensão deve ser incluída na política de responsabilidade social das instituições de ensino superior. Na verdade, a sua política socialmente responsável deve ser pensada como um projeto onde o ensino, a investigação e a extensão atuam de forma integrada.

Embora, pelo menos em Portugal, as universidades públicas tenham vindo a integrar estes princípios, a verdade é que as elevadas exigências resultam, também em grandes desafios. Assim, em seguida pretende compreende-se de que forma a responsabilidade social tem sido aplicada nas instituições de ensino superior públicas portuguesas, tendo em conta esta articulação dos três pilares da sua missão: ensino, investigação e extensão.

\section{METODOLOGIA}

Partiu-se, então, para este estudo com os objetivos de compreender (1) a relevância da responsabilidade social nas universidades públicas e (2) a forma como os três pilares da sua missão - ensino, investigação e extensão 
- se destacam e se articulam como mecanismos responsáveis pela concretização de um comportamento socialmente responsável. Para tal teve-se como referência o ensino superior público português.

Como metodologia deste estudo (que, na verdade, pensamos como piloto de uma investigação mais alargada a desenvolver na tese de doutoramento), optou-se por desenvolver um conjunto de entrevistas, para explorar as perspetivas e perceções de especialistas nesta temática. Como modalidade foi selecionada a entrevista semi-estruturada - ou seja, com um questionário aplicado mediante um guião previamente definido -, que possibilitou alcançar um maior grau de profundidade nos assuntos evitando dispersão ou afastamentos do tema. As entrevistas foram realizadas entre os meses de maio e junho de 2016.

No grupo de entrevistados foram incluídos quatro responsáveis de comunicação de universidades públicas portuguesas. Assim, foram entrevistados: E1, da Universidade do Porto (UP), E2, da Universidade da Beira Interior (UBI), E3 da Universidade do Minho (UM) e E4 do ISCTE - IUL. A opção por entrevistar os responsáveis de comunicação justifica-se, na medida em que a responsabilidade social está, normalmente, centrada nos gabinetes de comunicação das organizações.

As entrevistas tinham como objetivos principais: (a) conhecer a visão destes profissionais em relação à relevância da responsabilidade social na ação e comunicação das universidades; e (b) perceber o grau de aplicação de políticas desta natureza nas universidades públicas em geral, e nas suas instituições de atuação em particular. Assim, as questões colocadas procuraram analisar: (i) o papel das universidades no progresso social, (ii) a forma que estas adotam para mostrar um comportamento socialmente responsável e; (iii) a relevância do ensino, da investigação e da extensão como mecanismos de responsabilidade social.

\section{DISCUSSÃO}

Genericamente, a análise das entrevistas realizadas veio corroborar o debate descrito na revisão da literatura, na medida em que demonstrou que as universidades públicas portuguesas (consultadas) se reconhecem como espaços responsáveis pelo desenvolvimento social e estão conscientes da importância de terem uma atuação socialmente responsável. Na linha de Ribeiro (2013), a qualidade do ensino superior parece estar na agenda das 
discussões sobre o seu processo de modernização, assim como o seu papel no progresso social. E constatou-se, igualmente, que, o compromisso com a responsabilidade social nestas instituições não se esgota nas atividades de extensão, mas, estende-se às práticas de ensino e investigação. Explicaremos estas ideias nos próximos pontos, em que dividimos a análise das entrevistas.

\title{
6.1 A RELEVÂNCIA DA RESPONSABILIDADE SOCIAL NAS UNIVERSI- DADES PÚBLICAS PORTUGUESAS
}

Segundo apuramos, as universidades portuguesas de hoje desenvolveram uma consciência clara do papel que desempenham no progresso da sociedade. Tal é demonstrado pelas declarações dos vários responsáveis de comunicação entrevistados. E2/UBI confirmou que, nos últimos anos, se tem destacado uma terceira missão das universidades ligada, precisamente, ao seu compromisso para com a sociedade. E3/UM, afirmou: "as instituições de ensino superior, nomeadamente as públicas como a Universidade do Minho, têm espelhado na sua missão um sério compromisso com a sociedade". E E1/ UP, destacou, igualmente, este protagonismo no desenvolvimento social, ao referir:

\begin{abstract}
As universidades possuem, na sua missão, dois pilares fundamentais: o ensino e a investigação. Mas atualmente tem-se destacado um terceiro aspeto que tem a ver com as atividades de extensão à sociedade e, consequentemente, com a responsabilidade social a que as universidades dão cada vez mais atenção.
\end{abstract}

E2/UBI concorda com este facto, destacando que "a evolução da sociedade tornou a intervenção ao nível da responsabilidade social quase uma obrigação para as universidades, (... )". E4/ISCTE-IUL contribuiu para o debate, afirmando que:

Ao nível da responsabilidade social, as Universidades devem procurar ter em consideração o impacto das suas decisões e atividades na comunidade interna e externa, incluindo a preocupação com a igualdade e a justiça social, bem como sobre o ambiente nas suas diversas dimensões (...).

A par da consciência clara do papel das universidades no desenvolvimento social, os entrevistados destacaram outros factos relevantes. E1/ 
UP, declarou que os estudantes dão importância crescente às questões da responsabilidade social e que, para acompanharem a sua forma de estar e para melhor comunicarem com este público, estas instituições de ensino, necessitam de assumir um compromisso com um comportamento socialmente responsável e valorizar uma atuação que privilegie a resposta às necessidades sociais. E2/UBI refere que este compromisso pode ser cumprido de todas as formas que fortaleçam o vínculo com as comunidades locais e regionais, através de respostas criativas aos desafios e problemas emergentes. Para E4/ISCTE-IUL as universidades devem ter a responsabilidade social como um ativo presente nas suas práticas de gestão, no ensino, na investigação e na extensão.

Entende-se, portanto, que, estas instituições, enquanto espaços privilegiados de produção de conhecimento e de descobertas científicas, devem mobilizar o desenvolvimento de ações e comportamentos que apoiem a busca de respostas aos problemas que emergem na sociedade. Na linha do que refere a literatura, como Pinto (2009) que afirma que é muito importante que estas se coloquem numa postura socialmente responsável para com os indivíduos implicados diretamente no processo de educação, mas também, para com todos os outros que sofrerão consequências com esse processo.

\subsection{A RELEVÂNCIA DA RESPONSABILIDADE SOCIAL NAS UNI- VERSIDADES PÚBLICAS PORTUGUESAS}

Como vimos já, ensino, investigação e extensão representam os três pilares da missão das universidades. E é através destes ativos que se cumpre a sua função. Porém, estes têm, também, um importante impacto social. E não é apenas através da extensão que a universidade firma o seu compromisso social, pois, o ensino e a investigação representam um papel crucial no progresso da sociedade. Ora, esta leitura foi igualmente encontrada nas perceções dos entrevistados.

E1/UP acredita que ensino, investigação e extensão mostram que há um contributo inegável das universidades em prol do desenvolvimento das sociedades. Declara, ainda, a respeito do ensino, que: 
ciedades possam evoluir, possam continuar a desenvolver-se.

Para E3/UM a relevância da educação manifesta-se "na responsabilidade da formação humana nas diferentes dimensões ética, cultural, científica, artística, técnica e profissional, disponibilizando uma oferta educativa diversificada", bem como "na aposta na valorização dos seus públicos internos: docentes, investigadores, pessoal não docente e estudantes, contribuindo para o seu bem-estar, formação e exercício da cidadania". E4/ISCTE-IUL contribuiu para este debate referindo que, por via do ensino, a responsabilidade social se manifesta mediante a inserção de temáticas relacionados com este tema, nos programas das unidades curriculares. E2/UBI complementa estas visões, ao pensar o ensino como uma ferramenta que serve a sociedade de várias formas:

Por via do ensino, pela fixação de um corpo científico e técnico devidamente qualificado e pela formação de diplomados altamente especializados, necessários ao desenvolvimento económico, social e cultural da Região, os quais desempenham um papel importante na fixação de novas empresas em sectores diversificados, com a transferência de conhecimentos incorporados através de recursos humanos (alunos de pós-graduação, doutoramento e pós-doutoramento).

Verifica-se, então, o reconhecimento que o contributo do ensino para o progresso da sociedade é inegável e, por isso mesmo, a sua atuação deve ser fazer parte do plano de responsabilidade social das universidades. Como lembra Cabrito (2004), a educação, maioritariamente praticada nos estabelecimentos de ensino superior, favorece processos de autoformação e de atualização profissional, que são indispensáveis na adaptação às inovações e mudanças que caracterizam a sociedade atual, contribuindo para a melhoria da qualidade de vida.

Mas também a investigação representa um mecanismo decisivo para o desenvolvimento sustentável das sociedades. E a pesquisa desenvolvida deve hoje ser motivada pelas necessidades sociais que vão surgindo, não podendo estar desvinculada da realidade (Pinto, 2009). Este entendimento é, igualmente, partilhado pelos nossos entrevistados.

Para E1/UP o contributo da investigação é claro:

Os avanços que a mesma permite em várias áreas são o motor das nossas sociedades. Veja-se, por exemplo, a evolução positiva da es- 
perança média de vida ao longo dos anos. Tudo isto se deve à investigação e muita dela é, de facto, gerada nas universidades. Refiro-me, aqui, não só à UP mas a todas as universidades do país e do mundo.

Também para E2/UBI o contributo da investigação é impar. Localizado em unidades de pesquisa universitárias, permite o desenvolvimento de “(... ) centros de excelência em investigação em diversas áreas e a produção de conhecimento traduzido no registo e licenciamento de patentes". E3/UM completa esta tese referindo que devem ser promovidas práticas “(...) de investigação de excelência na busca de soluções inovadoras que respondam aos grandes desafios da sociedade". As descobertas e avanços científicos que resultam da pesquisa representam, normalmente, as forças que permitem à sociedade evoluir, respondendo aos seus problemas e sociedades. Neste sentido, a investigação não pode ser ignorada como parte fundamental da política de responsabilidade social das instituições de ensino superior, até porque, como afirma Cabrito (2004), as universidades e os seus institutos e laboratórios continuam a produzir a maior parte da investigação científica. Desta forma, são responsáveis por complementar a capacidade de inovação das empresas, aumentando a competividade das regiões (Hegde, 2005).

Já a extensão diz respeito a práticas de aproximação da universidade à sua comunidade (Reis e Bandos, 2012). Assim, a sua manifestação dá-se por meio de um conjunto de iniciativas que procuram dar resposta às carências da comunidade envolvente, por via de processos (mais ou menos formais) de transferência do conhecimento. Nos últimos anos, esta, passou a constar (de modo mais oficial) na missão das instituições de ensino superior, sendo-lhe atribuída a mesma relevância que ao ensino e à investigação.

No que respeita à interação com a sociedade, E3/UM define-a como:

(...) a transferência de conhecimento para o tecido económico empresarial envolvente, promovendo iniciativas empreendedoras, atividades culturais, intercambio dos diferentes saberes, contribuindo para o desenvolvimento social e económico, nos contextos regional, nacional ou internacional.

Já E4/ISCTE-IUL enfatizou a relevância da extensão ao afirmar o envolvimento das instituições,

Na extensão universitária pela participação em projetos e atividades especificamente dirigidos à resolução de problemas sociais em 
parceria com instituições públicas e do terceiro setor, promovendo o desenvolvimento social e económico da comunidade envolvente.

E1/UP colaborou para esta discussão, enfatizando um conjunto de iniciativas de extensão que fazem parte do plano de responsabilidade da sua universidade, referindo que "neste momento, a UP está também a investir bastante na transferência do conhecimento, com a sua aplicação concreta na sociedade". De acordo com os estes relatos, a UP tem, agora, um pelouro ligado às questões da responsabilidade social e as ações nesta área têm-se intensificado. Neste momento, esta Universidade apoia um conjunto de projetos de responsabilidade social, que vão desde o apoio a refugiados até à criação do Parque da Ciência e Tecnologia da Universidade do Porto que agrega um grupo de start-ups e centro de investigação, responsáveis pela geração de um elevado número de empregos.

Na mesma linha, E2/UBI afirma que a UBI está, também, atenta à extensão,

(... ) através do encorajamento à criação de empresas (spin-offs), do estabelecimento de parcerias com o serviço público, do estabelecimento de contratos com a indústria por forma a envolvê-la na produção de conhecimento, bem como da participação na articulação e implantação dos parques tecnológicos.

E3/UM esclareceu que, no contexto da extensão, a UM desenvolve um conjunto de iniciativas, destacando: o incentivo à prática do desporto; a criação do Fundo Social de Emergência - que apoia os estudantes com dificuldades económicas e; o investimento em projetos de investigação em parceria com empresas, que contribuem para a melhoria das condições de vida da comunidade e para a criação de emprego.

Em suma, apesar de se concentrarem nas ações concretas das suas instituições, os entrevistados reconhecem que, atualmente, as questões da responsabilidade social se estendem a todas as instituições de ensino superior, quer as nacionais quer as internacionais, e incluem todas as dimensões das suas atividades. $O$ que nos permitiu concluir que ensino, investigação e extensão devem caminhar de mãos dadas no cumprimento do compromisso de uma marca com o progresso social, o que é cada vez mais exigido às universidades. 


\section{CONCLUSÃO}

As universidades são instituições orientadas para o desenvolvimento social. Ao longo dos anos, o seu protagonismo como organizações destinadas à promoção e difusão do conhecimento e da cultura foi-se ampliado e, atualmente, são vistas como os espaços de excelência no progresso social. Espera-se que, mais do que ampliar e propagar a ciência, estas representem centros de resposta aos desafios e necessidades da sociedade.

A presente investigação permitiu reforçar os entendimentos encontrados na literatura para outros contextos internacionais, concluindo-se que as universidades públicas portuguesas parecem ter desenvolvido uma consciência crescente do seu papel decisivo no progresso social do país e do espaço externo. Nesse sentido, estas organizações veem respondendo com o fortalecimento de políticas de responsabilidade social, aspeto que se pode comprovar pelo reforço visível da importância atribuída ao terceiro pilar da sua atuação, ligado à extensão e à interação com a sociedade. Constatou-se, igualmente, que o compromisso com uma atitude socialmente responsável, embora se encontre muito associado às atividades de extensão - que são cada vez mais numerosas e diversas -, é igualmente associado ao ensino e à investigação, como determinantes motores de evolução social.

No que respeita a limitações encontradas no processo da investigação, destaca-se a dificuldade em contactar algumas instituições, sendo que o objetivo inicial era entrevistar um número maior de diretores de comunicação. Contudo, apesar das tentativas, o contacto revelou-se difícil. E é, ainda, de referir que será muito relevante estender estas entrevistas aos atores políticos destas instituições, responsáveis pelas definições estratégicas em matérias nucleares e que incluem a responsabilidade social. Ainda assim, julgamos que os resultados obtidos neste estudo piloto são pertinentes para fortalecer a tese defendida: de que há uma consciência crescente da importância do exercício da responsabilidade social nas diferentes dimensões da missão das universidades, entre as instituições de ensino superior público portuguesas.

Em termos de estudos futuros, para além do alargamento dos instrumentos de recolha de dados para cumprir os objetivos do estudo presente, julgamos relevante aplicar a análise ao sistema de ensino superior privado e ao ensino politécnico, com o objetivo de perceber quais as semelhanças e diferenças que existem, no emprego da política de responsabilidade social, 
nas diferentes instituições que complementam o ensino superior português.

\section{REFERÊNCIAS}

Balonas, S. (2014). Olhar o Público Interno: Fator Crítico nas Estratégias de Responsabilidade Social. Comunicação organizacional e Relações Públicas: horizontes e perspetivas, 73-86. Relatório de um debate. Centro de Estudos de Comunicação e Sociedade.

Bisset, W. (2014). The Role of Mission in Strategic Planning Development and Execution at a Lasallian Catholic University, Procedures and External Environment. Estados Unidos. Tese de Doutoramento. Seton Hall University Dissertations and Theses.

Cabrito, B. (2004). O Financiamento do Ensino Superior em Portugal: entre o Estado e o Mercado. Educ. Soc., Campinas. 25 (88), 977-996.

Dahan, G. \& Senol, I. (2012). Corporate Social Responsibility in Higher Education Institutions: Istanbul Bilgi University Case. American International Journal of Contemporary Research. 2 (3), 95-103.

Hegde, D. (2005). Public and Private Universities: Unequal Sources of Regional Innovation? Economic Development Quarterky. 19 (4), 373-386. Sage Publications. Doi: $10.1177 / 0891242405280111$.

Kreitlon, M. (2004). A Ética nas Relações entre Empresa e Sociedade: Fundamentos Teóricos da Responsabilidade Social Empresarial. XXVIII ENANPAD, Curitiba, 2004.

Maciel, A., Kowalsky, A. \& Menezes, V. (2009). A Responsabilidade Social das Instituições de Ensino Superior: Um Estudo a Partir das Práticas em Desenvolvimento no Rio Grande do Sul. IX Colóquio Internacional sobre Gestão Universitária na América do Sul, 27-25 de novembro, Brasil.

Nejati, M., Shafaei, A., Salamzadeh, Y \& Mohammadreza, D. (2011). Corporate social responsibility and universities: A study of top 10 world universities' websites. African Journal of Business Management. 5 (2), 440-447.

Pinto, M. (2009). Responsabilidade Social em Universidade Comunitária: Novos Rumos para a Educação Superior. (tese de doutoramento). Pontifícia Universidade Católica do Rio Grande do Sul, Brasil.

Pompeu, R. (2011). A Responsabilidade Social da Universidade na Formação de Capital Humano como Ferramenta de Desenvolvimento Local Sustentável.: os casos da UTAD e da UNIFOR (tese de doutoramento). Universidade de Trás-os-Montes e Alto Douro.

Pontes, J. \& Possamai, O. (2002). Responsabilidade Social das Organizações - Um Modelo para Priorizar as Necessidades Sociais da Região onde a Organização está inserida. XXII Encontro Nacional de Engenharia de Produção, Curitiba, outubro 2002.

Reis, A. L. \& Bandos, M. F. C. (2012). A Responsabilidade Social de Instituições de Ensino Superior: Uma Reflexão Sistêmica tendo em Vista o Desenvolvimento. Revista Gestão e Conhecimento. Edição Especial - 8. ${ }^{\circ}$ Congresso Brasileiro de Sistemas. 423 - 432.

Ribeiro, R. (2013). Responsabilidade Social Universitária: A Dimensão Humana da Qualidade Da Educação Superior. Caiu em Revista. 2, 106-121. 
Ribeiro, R. \& Magalhães, A. (2014). Política de Responsabilidade Social na Universidade Conceitos e Desafios. Educação, Sociedade e Culturas. 42, 133-156.

Sgorla, F. (2009). A Responsabilidade Social das Organizações Privadas: das Práticas à Gestão. Revista Alcance - Eletrônica. 16 (3), 392-403.

Sousa Santos, B. (2004). A Universidade no Século XXI para uma reforma democrática e emancipatória da Universidade. (3. ${ }^{a}$ ed). São Paulo: Cortez Editora.

Sousa Santos, B. (1994). Da Ideia de Universidade à Universidade de Ideias. Revista Crítica de Ciências Sociais. 27/ 28, 11-62.

Vasilescu, R., Barna, C., Epure, M. \& Baicu, C. (2010). Developing university social responsibility: A model for the challenges of the new civil society. Procedia Social and Behavioral Sciences. 2, 4177-4182. 


\section{Sónia Melo da Silva}

Licenciada em Ciências da Comunicação, no ano de 2012 e Mestre em Ciências da Comunicação, com especialização em Publicidade e Relações Públicas, desde 2014 pela Universidade do Minho. Pesquisadora da Fundação para a Ciência e a Tecnologia (FCT), e doutoranda em Estudos da Comunicação: Tecnologia, Cultura e Sociedade.

E-mail: sonia.c.melo.silva@gmail.com

\section{Teresa Ruão}

Doutorada em Ciências da Comunicação, pela Universidade do Minho, em 2008, é Professora Associada do Departamento de Ciências da Comunicação, Vice-Presidente do Instituto de Ciências Sociais da Universidade do Minho e Presidente do Conselho Pedagógico no mesmo instituto da Universidade do Minho.

E-mail:truao@ics.uminho.pt

\section{Gisela Gonçalves}

Doutora em Ciências da Comunicação; chefe do Departamento de Comunicação e Artes da Universidade da Beira Interior, é professora do Mestrado em Comunicação Estratégica da Universidade da Beira Interior e pesquisadora integrada no centro de pesquisa LabCom.Ifp.

E-mail: gisela.ubi@gmail.com 